\title{
El fragmento de tapa de sarcófago paleocristiano de Elda *
}

\author{
Antonio M. Poveda Navarro **
}

En enero de 1981 se halló, en el castillo de Elda, un fragmento de sarcófago de mármol blanco con vetas azules. La pieza apareció en la limpieza de la cubierta de la cisterna del patio central ${ }^{1}$, donde se ubicaba reutilizada como una piedra más en el abovedamiento de aquélla. Recientemente (invierno de 1984), se ha completado un poco más la pieza, ya que se recogió un nuevo fragmento, más reducido que el anterior, con el cual encaja perfectamente. Esta vez el hallazgo fue en el interior de la cisterna, donde caería al desprenderse de la techumbre de la misma, lugar en el que todavía se conservó la otra parte de la piedra hasta su descubrimiento.

La circunstancia de que la pieza aparezca reutilizada en una fortaleza medieval es totalmente normal, pues como expresa Palol (1967, 289), muy frecuentemente los sarcófagos se hallan reutilizados en tiempos medievales y modernos.

\footnotetext{
* Este artículo es el resultado de algunas de nuestras investigaciones realizadas en Italia, en los veranos de los años 1986 y 1987, gracias a que fuimos becados por la Excelentísima Diputación Provincial de Alicante, de la que quedamos en gran manera deudores por su inestimable apoyo.

Hemos de agradecer, también, las facilidades y ayuda que nos ofreció el personal de los Musei, Archivio Fotografico y Biblioteca del Vaticano, en cuantas visitas realizamos en razón de nuestra investigación.

** Museo Arqueológico de Elda.

- Las labores de limpieza y desescombro del patio central del castillo corrieron a cargo de la Sección de Arqueoiogía del Centro Excursionista Eldense, que fue la descubridora de la pieza que tratamos.
} 
La nueva parte recuperada completaba el flanco izquierdo del primer hallazgo, que resulta pertenecer a una tapa de sarcófago paleocristiano, con la representación del ciclo del profeta bíblico Jonás, cuyas escenas se aprecian parcialmente.

Los restos de la tapa se encuentran depositados en el Museo Arqueológico Municipal de Elda.

Esta interesante obra paleocristiana ha merecido, hasta la fecha, un artículo divulgativo y tres notas en otras tantas publicaciones de carácter general (Llobregat, 1981; 1985, 387; 1986.a, 195; 1986.b, 72).

\section{DESCRIPCIÓN}

La parte de tapa que nos ha quedado tiene $66 \mathrm{~cm}$ de longitud, 37 $\mathrm{cm}$ de altura y $10 \mathrm{~cm}$ de grosor. Estamos ante una pesada placa de

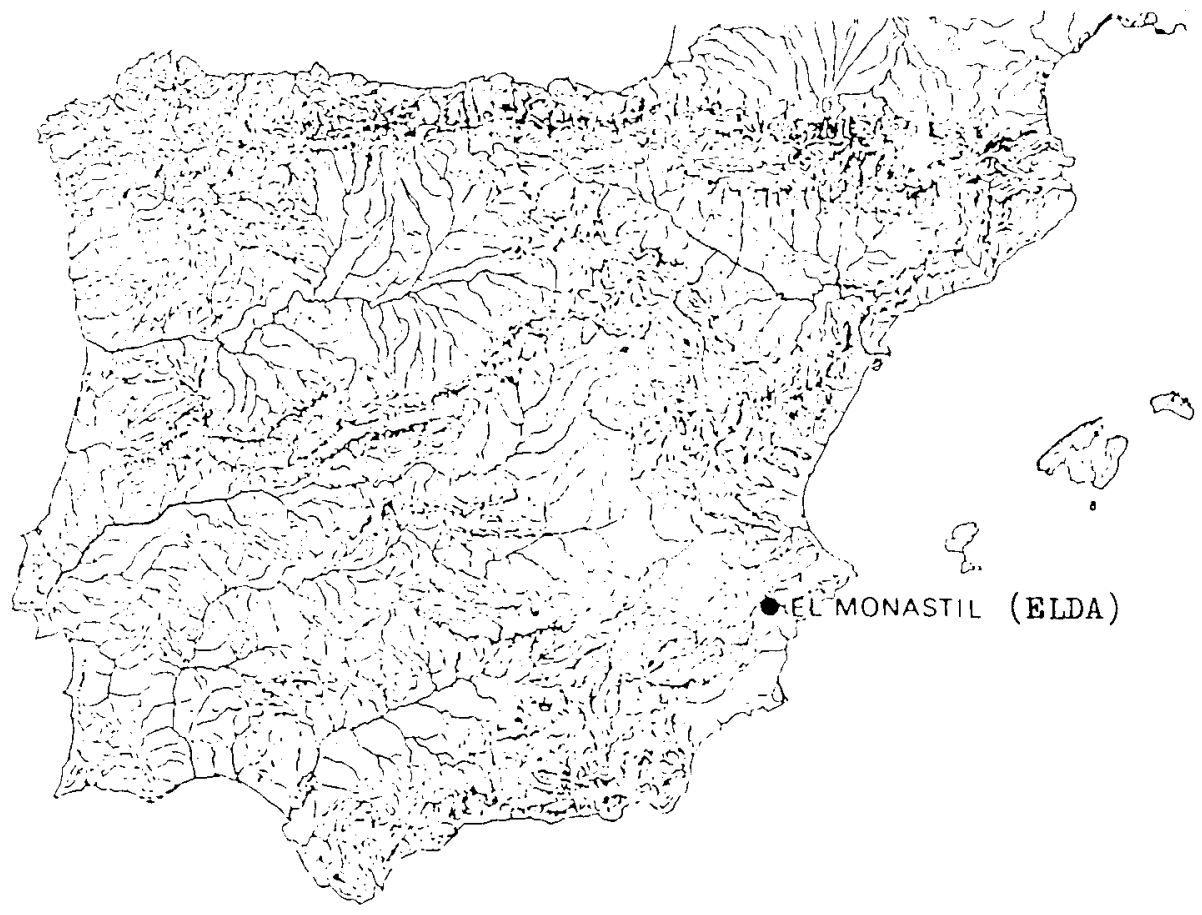

Fig. 1. Situación del poblado de El Monastil en el sudeste de la Península Ibérica. 
mármol italiano, de Carrara ${ }^{2}$, que completa pudo alcanzar $2,10 / 2,20 \mathrm{~cm}$ de longitud, de modo que se correspondería con un sarcófago de los fabricados en grandes dimensiones, y cuyo frente pudo contener relieves en doble friso, al menos eso intuimos de sus paralelos formales y cronológicos.

Las medidas de los elementos decorativos de la tapa son: $31 \mathrm{~cm}$ altura de la cartela, que tiene $30-40 \mathrm{~cm}$ de longitud, y $5 \mathrm{~cm}$ de ancha la moldura que la enmarca. La nave tiene $39 \mathrm{~cm}$ de eslora (longitud de proa a popa) y $6 \mathrm{~cm}$ de línea de flotación. El palo mayor tiene $21 \mathrm{~cm}$ de altura. La vela alcanza $20 \mathrm{~cm}$ de anchura máxima. El personaje de proa tiene $17 \mathrm{~cm}$ de altura por $7,5 \mathrm{~cm}$ de ancho, el personaje del centro 18 $\mathrm{cm}$ por 7,5 , y el de popa 17 por $8 \mathrm{~cm}$. La altura de los monstruos marinos es $24 \mathrm{~cm}$, alcanzando $12 \mathrm{~cm}$ de longitud el primero (el de la izquierda). Y Jonás tiene $16,5 \mathrm{~cm}$ de desarrollo longitudinal.

La representación en relieves de estas figuras compone escenas del ciclo del profeta Jonás. En la primera escena éste es arrojado a la mar en medio de una tempestad, hecho que es aprovechado por un gran monstruo marino para engullirle. En la siguiente fase escénica el profeta es vomitado por el animal referido, que le depositaría en la playa. La tercera y última fase nos presenta a Jonás reposando plácidamente debajo de la calabacera, adoptando la postura del clásico Endymión (Jonás, I, págs. 12-16; II, págs. 1-10; III, pág. 10; IV, pág. 1; IV, págs. 8-9).

Esta historia biblica aparece parcialmente representada en la parte derecha de la tapa, como se aprecia cuando la observamos frontaimente.

En la parte izquierda de la pieza se puede contemplar buena parte de la tabella inscriptionis, que en esta ocasión es una cartela central anepigráfica, pues no parece que hubiese tenido la inscripción sepulcral que a veces se coloca en ella. A los flancos de la cartela los relieves adoptarían una disposición simétrica.

A partir de esa tabella rectangular, o cuadrada, y de izquierda a derecha, tenemos representadas la primera escena del ciclo e indicios de la segunda y tercera. Asi, observamos primero una embarcación de vela cuadra, que surca el mar entre fuertes olas. En ella apreciamos, desde la popa hasta la proa, el aplustre (adornado de popa), el timonel que

${ }^{2}$ El análisis de una muestra de mármol del sarcófago reveló su procedencia de una cantera de Carrara. Agradecemos profundamente al profesor A. Álvarez y a J. Ventura, colaboradora de su equipo de laboratorio, de la Universidad de Bellaterra, Barcelona, quienes realizaron desinteresadamente tal análisis. 
lleva el gobernaculum o gobernalle, constituido por un notable remo de pala. Tras él quedan jarcias y gavia de la vela mayor. Delante del timonel un personaje sujeta parte del cuerpo de otro (que pertenece a Jonás), cuyas piernas se cin̄en a las axilas de aquél, que le está arrojando a las fauces de un monstruo marino, que comienza a engullirle. El último personaje de la nave, el más cercano a proa, aparece llevándose las manos a la cabeza, en señal de duelo, o quizá para taparse el rostro y no contemplar la dramática escena. A continuación reaparece el dragón marino, que representa la escena segunda, en la que el profeta es devuelto. Por debajo de estas dos primeras escenas observamos un fuerte oleaje con remolino incluido. Entre las olas se entrevén las garras del cetáceo bíblico. La existencia de la tercera escena, la final, se intuye mínimamente por la presencia, a la derecha de la segunda representación del monstruo, del inicio de la cucurbita o calabacera bajo la que descansaria Jonás. Exactamente, detectamos, sobre el mismo borde de la tapa, un pequeño circulito realizado con el trépano, y del que pende otro elemento diminuto, quizá una hoja. La situación y la morfología de estos dos elementos son semejantes a los que componen la calabacera de otras tapas idénticas a la de Elda, por lo tanto estamos convencidos de que también en ésta aparecia la escena del reposo del profeta.

\section{EL CICLO DE JONÁS EN EL ARTE PALEOCRISTIANO}

\subsection{Interpretación del tema}

La historia de Jonás es uno de los episodios más característicos y queridos en el arte paleocristiano funerario, por el hecho de que el profeta, señalado por el propio Jesús como precursor y ejemplarización de su propia muerte y resurrección (Mat. XII, págs. 40-41), tiende a convertirse en símbolo de la esperanza de resurrección del mismo difunto (Engemann, 1973, págs. 70 y ss. Murray, 1981, págs. 75, 93. Belli, 1985, págs. 146-149).

Esta historia se representó constantemente, porque era la que mejor simbolizaba tal resurrección, y la que mejor respondía a la estrategia del arte cristiano del siglo III, que recurre a algunas imágenes emblemáticas, de recuerdo alegórico, que se repiten de manera incansable para mantener siempre viva aquella esperanza de salvación. Por otra parte, esa repetitividad iconográfica evidencia la relativa pobreza del repertorio cris- 
tiano preconstantiniano (Christie, 1984, pág. 12), de modo que siempre se acude a las representaciones de Jonás, pero también a las de Noé en el arca, Isaac librado del sacrificio, los tres jóvenes hebreos en el horno babilónico, Daniel entre los leones, el Buen Pastor, la Orante y el Cristo-Maestro.

De las tres escenas que componen el ciclo: Jonás arrojado al mar donde le engulle el monstruo marino; Jonás vomitado por éste, y Jonás reposando bajo la calabacera, es esta última la que realmente importaba destacar, pues las primeras simbolizan la resurrección, que sirve solamente como paso previo para el reposo eterno, que es el fin último de la representación de la historia del profeta.

Esta interpretación explicaría el hecho de que la representación de Jonás bajo la calabacera ocupe, en algunas ocasiones, la zona central del frente de algunos sarcófagos, como es el caso del sarcófago de Leiden (Brunsting, 1959, págs. 35-40).

De la misma opinión son Stuiber, Stommel y Engemann (respectivamente, 1957 , págs. $136-151 ; 1958$, págs. 112-115; 1973, pág. 74), pues afirman que en la iconografía del ciclo sobre sarcófagos no se ensalza la salida del profeta del interior del cetáceo, como ocurriría en el caso de desearse resaltar la resurrección, sino que la pretensión es destacar el descanso más sereno posible, cuyo concepto parece depender de la tradición helenistica.

En igual línea que los anteriores, Delgado (1976, págs. 321-322) entiende que las escenas de Jonás recuerdan la liberación de un hombre concreto, que castigado a morir ahogado en el mar, por su negativa a predicar entre los gentiles, es final y milagrosamente transportado al feliz descanso bajo un ambiente paradisíaco, cuyo sentido simbólico es el del reposo eterno del difunto. De esta forma el profeta está evocando al muerto sepultado en el sarcófago, cuya alma goza ya de un lugar en el paraíso celeste, mientras su cuerpo disfruta de un sueño o reposo placidísimo esperando la resurrección.

La justificación de la interpretación de la escena de Jonás en reposo la encuentra Ferrua (1962, págs. 54-57) en el propio texto sagrado, en el que estaría su origen. Además, entiende la escena de la misma forma que los ya citados, y señala que aquélla es símbolo de la beatitud del difunto.

Para conseguir una mayor sensación de descanso apacible, se asocia a dicha escena la representación de ambientes bucólicos de paz y tranquilidad, de aquí se explica el hecho de que aparezcan figuras de 
pastores ( $y$ en menor medida de pescadores). Ejemplos de tales asociaciones, sin ser exhaustivos, los tenemos en el ya citado sarcófago de Leiden, en el Córdoba 3.3 (Sot. 20), el de Berlín (WS. 54,3), el de Santa María Antigua (WS. 1,2; 3, 2, y Rep. 747), el de Pisa (WS. 88, 1,3; 5,7), y en tapas como la de Baebia Hertofila (WS. 53,3; Rep. 778), y la de Villa Doria-Pamphili (WS. 10,1; Rep. 958). Este tipo de escenas bucólicas eran tomadas de las tradicionalmente representadas en sarcófagos romanos paganos.

Engemann (1973) opina que fue posible la unión de ambos temas porque el tema pastoril era neutral, y muy conocido en los talleres de fines del siglo III, además de que encajaba perfectamente su significado con el de Jonás descansando, pues la recreación de la paz y la felicidad de la vida sencilla es identificable con la imagen del deseo de paz eterna para los difuntos.

Esta asociación iconográfica también fue analizada y verificada por Sotomayor (1975, págs. 123-124), que ratificó la interpretación dada por los autores mencionados anteriormente, y vio una distinción temáticocronológica: entre los sarcófagos más antiguos con la representación del ciclo es frecuente resaltar más, sobre todo la última escena, la del reposo, mientras que «en los sarcófagos del siglo iv y en sus tapas, vuelve a ser normal la representación completa y equiparada de todo el ciclo".

\subsection{Elementos figurados en el ciclo sobre sarcófagos}

El arte pagano helenístico y romano fue la cantera de donde el artista paleocristiano se surtió, cristianizando todos aquellos elementos que necesitaba, de lo cual tenemos abundantes ejemplos en los sarcófagos cristianos primitivos, tal y como vamos a comprobar con el análisis del que presenta la historia de Jonás.

Las escenas marítimas, donde aparecen marineros en naves que surcan la mar, eran ya frecuentes en sarcófagos paganos (Lawrence, 1962, págs. 289-291, pl. 77, 1-3). El mismo tipo de marineros, velas, remos, embarcaciones, oleaje, etc., que se habian representado en aquéllos, pasan ahora a las obras sepulcrales cristianas.

El monstruo marino (la «ballena" de Jonás) que aparece en el sarcófago paleocristiano es del tipo comúnmente representado en el mundo mitológico pagano, de la cuenca del Mediterráneo, tal y como lo conoce- 
mos en las pinturas vasculares griegas y en las pinturas parietales pompeyanas, relacionadas con los mitos de Andrómeda y Hesione, y en el animal de fantasía, "kétos", cuya forma aparece tipificada por los "thiasoi" marinos representados sobre sarcófagos paganos de los siglos $11 \mathrm{y}$ III d.C. (Rumpf, 1939, págs. 94-99, 112-115, pls.: 13, 46; 20, 57; 46, 120; $58,307,318 ; 60,315$. Lawrence, 1962, págs. 294-295. Garcia y Bellido, 1979, pág. 672. Belli, 1985, pág. 156).

Este precedente de bestia marina, conocida familiarmente como hipocampo (caballo de Venus), contenia un concepto muy atractivo a la estrategia iconográfica cristiana, ya que era símbolo de la regeneración para la filosofía epicúrea, y esta idea era perfectamente asimilable dentro de la concepción de la resurrección cristiana (Pijoan, 1954, pág. 72).

La figura de Jonás en reposo bajo la calabacera, cucurbita o pérgola está entre las primeras utilizadas en el ámbito funerario cristiano; su significado e inspiración parecen estar en la escena del reposo y ambientación bucólica de los sarcófagos paganos con las figuras míticas de Endymión y Ariadna (Lawrence, 1962, pág. 292. Belli, 1985, pág. 147), las cuales mediante sus relaciones con la divinidad aseguran al difunto que se identifica con ellas una especie de "apoteosis personal» (Engemann, 1973, pág. 73).

Ante la sugerencia general de que la escena del descanso del profeta deriva de una representación pagana, como lo es la de Endymión, han aparecido algunas opiniones contrarias a tal tesis, las más significativas son las de Ferrua y Stevenson (respectivamente, 1962, págs. 5457, y 1979, pág. 68).

El primero ha analizado el texto sagrado y ha encontrado en él el origen de la fase de reposo de Jonás, refutando radicalmente una inspiración conceptual de aquélla en elementos extrabíblicos.

El segundo no entra en la cuestión conceptual y si en la formal, ya que opina que la pretendida semejanza entre Jonás y Endymión seria simplemente la misma que existe entre una figura masculina apoyada en el suelo, y cualquier otra figura masculina que estuviese en igual posición.

De todos modos, es cierto que la postura de reposo utilizada en las represenaciones de Endymión y de Jonás es casi idéntica; así, es muy probable que la representación del primero fuese el antecedente formal, tipológico, del segundo. 


\subsection{Representación del ciclo de Jonás sobre diversas modalidades artísticas paleocristianas}

Las muestras iconográficas que recogen escenas de la vida de Jonás son abundantes en todo el arte paleocristiano, como hemos verificado después de realizar un breve repaso de éste.

En el campo pictórico es fácil ver escenas del profeta; así, en Roma, en la catacumba de los Santos Marcelino y Pedro, y en la de San Calixto, aparecen pinturas del ciclo, que se fechan, respectivamente, en los siglos II-IV y III (Mancinelli, 1981, págs. 23, 40-41). De finales de este último siglo son otras pinturas con igual tema, esta vez asociado a la representación de un pescador y de un pastor (tema bucólico y complementario, en ocasiones, del de Jonás). Este conjunto pictórico decora los muros del mausoleo de los Julios bajo el Vaticano (Palol, 1976, pág. 19).

Los avatares del profeta son ilustrados igualmente en los mosaicos. En la cúpula del mausoleo de Centcelles (Tarragona), de mediados del siglo IV, aparece el cielo junto a otras escenas bíblicas (Palol, 1967, págs. 128-129, lám. XIV). Otro mosaico, constantiniano, el del pavimento teodoriano de la basílica de Aquileya, recoge monumentalmente la misma historia (Brusin, 1933, págs. 198, 262, tav. 42-44. Kahler, 1982, págs. 89 y ss., tav. 25,1 y 2). Hemos de destacar dos obras más del arte musivario con este contenido: un mosaico hallado en 1940, debajo de San Pedro, donde aparece Jonás tragado, datado en el siglo Iv (Ghetti et alii, 1951, pág. 2, tav. 12 b), y otro pavimento, éste del siglo $v$, comienzos, muy semejante al de Aquileya, que procede de Hippo-Diarrhytus (Túnez) (Gauckler, 1910, pág. 15, pl. 5).

Conocemos piezas excepcionales que reflejan algunas fases del episodio bíblico. Así, procedente de Tarsos existe un altorrelieve de mármol con el profeta tragado y vomitado, fechado en la cuarta centuria (Lowrie, 1901, págs. 51-57, figs. 1, 2). Otro hallazgo único es el compuesto por cuatro estatuillas aparecidas también en Tarsos, que ilustran la historia de Jonás. Están realizadas en mármol y formaban parte del ornamento de una fuente, de la propiedad de una acaudalada familia cristiana. Se las ha datado en la segunda mitad del siglo III (Christie, 1984, págs. 12, 61 , fig. 17).

También vemos el asunto en la lipsanotheca de Brescia, de la segunda mitad del siglo IV, cuyas placas ebúrneas presentan talladas algunas escenas del Antiguo y del Nuevo Testamento, destacando en los 
frisos superiores largos el ciclo completo (Kollwitz, 1933; García y Bellido, 1979, págs. 767-769).

Incluso en la cerámica African Red Slip Ware, en sus piezas con decoración en relieve, formas Hayes $53,53.7,55.2$ y 56 , datables entre mediados del siglo iv y el primer tercio del $\mathrm{V}$, encontramos representados a Jonás y los monstruos marinos (Hayes, 1972, págs. 78-91, 216-217).

\section{LOS SARCÓFAGOS CON EL CICLO DE JONÁS Y LA TAPA DE ELDA}

Sin duda, donde la representación de las escenas de la vida del profeta alcanzan sus más frecuentes y mejores ilustraciones, es en los relieves de los sarcófagos paleocristianos, tanto en las cajas como en las tapas.

Los mismos temas de las pinturas catacumbales fueron adaptados a los sarcófagos por los cristianos (Grabar, 1967, pág. 240). Esta adaptación, en el caso concreto de nuestro ciclo, tuvo lugar a partir de mediados del siglo III (Belli, 1985, pág. 147), de modo que se convirtió en una de las más antiguas y primeras representaciones sobre sepulcros paleocristianos, generalmente asociadas a otros episodios bíblicos: Adoración de los Reyes Magos, los tres muchachos en el horno de Babilonia, Adán y Eva, escena de banquete y más raramente escena pastoril.

Las tapas de los sarcófagos serán el soporte preferido para representar el ciclo de Jonás, aunque no de forma excluyente respecto al resto del frente sepulcral.

Sabemos de la existencia, hasta hoy, de más de medio centenar de este tipo de piezas con tal tema. Una cuarentena de ellas procede de la zona Roma-Ostia, mientras que una docena de las mismas se distribuyen por España, sur de Francia (zona de Arlés) y resto de Italia, citados de mayor a menor número de hallazgos. Para su estudio contamos con las obras de varios autores, destacando por su importancia la de F. Gerke (1940, págs. 151-185; 366-370).

A mediados del siglo III 0 inicios de su segunda mitad pertenecen los primeros sarcófagos cristianos con la iconografía del ciclo, que hasta los inicios del siglo IV se convertiría en el tema principal, o uno de los principales, de los sepulcros donde era representado. A esta fase corresponden, por ejemplo, el sarcófago de Santa Maria Antica (Roma), que 


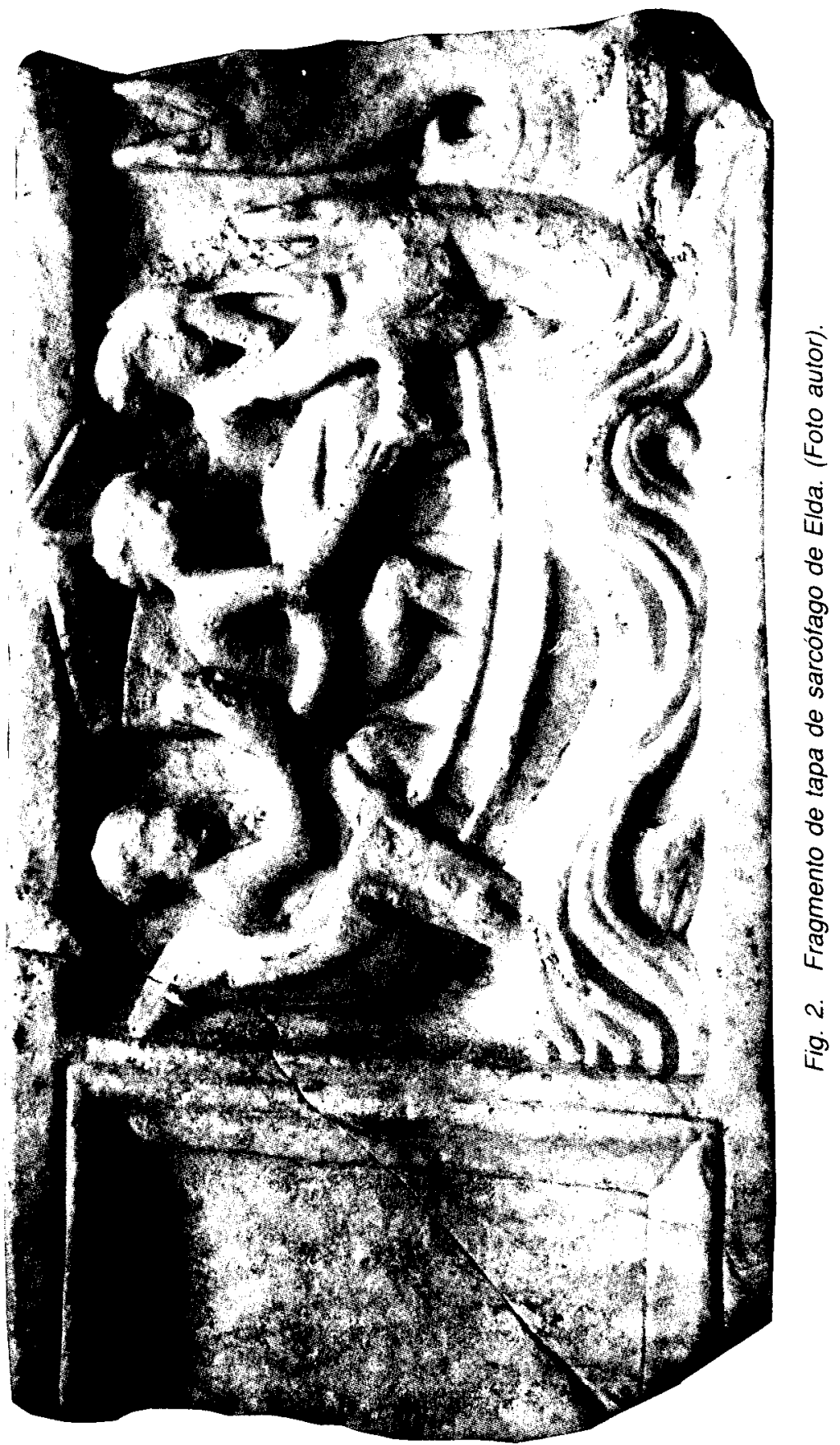


recoge el ciclo sobre la caja; el de Baebia Hertofilia, en el Museo Nazionale Romano (Roma), que lo contiene en la parte izquierda de una tapa, y el Laterano 119, en el Museo Pío Cristiano del Vaticano, que recoge la escena monumentalmente, y que quizá signifique el máximo apogeo en la representación de esta historia biblica.

El primer tercio del siglo IV representa una segunda etapa en la evolución de estas piezas funerarias con tales episodios, que aparecen ahora totalmente asentados, especialmente sobre tapas. De entre una larga lista de ejemplos, podemos citar la tapa del sarcófago de Aurelio, en el cementerio de San Lorenzo fuori le mura (Roma); otra de un sarcófago del Museo Nazionale Romano; la tapa de Pascasia, en el Museo de Arlés; varias tapas del antiguo Laterano, hoy en el Museo Pio Cristiano, y un largo etcétera, que es recogido, junto a las piezas citadas, en las obras fundamentales de Wilpert y Deichmann (respectivamente, 19291936; 1967).

El final de la fase anterior da paso a otra en la que la historia de Jonás queda relegada, pasando a ser una representación más de las que aparecen en los sepulcros cristianos de ese momento. Los mejores ejemplos de esta nueva situación son algunos sarcófagos con «imago clipeata", como uno del Museo de Arlés, y el Laterano 178, en cuyas cajas reflejan las escenas del profeta (respectivamente, WS. 122, 3; Rep. 44), que también las podemos apreciar en una de las últimas tapas decoradas con las mismas, como es el caso del sarcófago de columnas Laterano 152 (Rep. 52).

Después de esta última fase (335-350) de la evolución de la iconografía de Jonás sobre sarcófagos cristianos, y ya dentro de la segunda mitad del siglo IV, ella desapareció de las representaciones sobre éstos.

En España conocemos, sin contar la pieza de Elda, cinco casos en los que se representa el ciclo: dos en las enjutas de los arcos que decoran los respectivos sarcófagos de Los Palacios y Córdoba 3.3 (Sotomayor, 1975, págs. 122-124 y 129-130), y tres más en otras tantas tapas: la del sarcófago de Martos, apenas conservada (Recio, 1969, págs. 112114. Sotomayor, 1975, pág. 148), la empotrada sobre el arco toral de la iglesia de Santa María de Temes, en Lugo (Balil, 1975, págs. 313-316. Delgado, 1976, págs. 303-324), y la exigua parte de una tapa conservada en el Museo Sorolla de Madrid (Sotomayor, 1980, págs. 233-239).

Después de analizar, en directo o a través de la bibliografía, el largo elenco de tapas con la representación del ciclo de Jonás, debemos hacer notar que existen muchas de aquéllas que son muy semejantes entre sí, pero sin llegar a ser idénticas, siempre hay diferencias iconográficas y de 
estructura compositiva. Encontramos elementos diversamente representados y ubicados. Hay naves con velas y sin ellas, con la proa visible o tapada por el kétos, con tres marinos o con dos, el situado a proa aparece hacia la derecha o hacia la izquierda, en posición de orante (con los brazos alzados) o con sus manos ocultándole el rostro, el monstruo es representado engullendo a Jonás o contemplando cómo éste es arrojado al mar, la nueva representación del monstruo es aislada o vomitando al profeta, etc.

Estas y otras variantes, la dificultad de datar solamente por motivos estilísticos, todavía mayor en el caso de las tapas aisladas, sin su sarcófago (Sotomayor, 1980, pág. 234), y la lentitud de evolución del estilo en ellas, hacen que sea especialmente difícil datar una tapa, y más si es un fragmento como en el caso de Elda.

El primer y único intento de datar esta pieza corresponde a Llobregat (1981; 1985, pág. 387; 1986.a, pág. 195; 1986.b, pág. 72), que se inclina por situarla en el primer tercio o primera mitad del siglo IV. Tal data es correcta, pero tras nuestra investigación, creemos que podemos matizarla.

Hechos como que la escena aparezca a la parte derecha de la tapa, que la nave se representa completa, que los monstruos no dejen ver sus colas, que el personaje de proa no adopte la postura de orante y si la de llevarse las manos al rostro, y el uso leve o inexistente del trépano, nos hacen creer que esta tapa podría datarse entre los años 325-335.

La parte izquierda de la tapa a la que pertenece el fragmento de Elda debía recoger otros episodios biblicos. Gerke (1940, págs. 366-370) ha dividido las tapas de sarcófagos del siglo IV decoradas con el ciclo de Jonás en cinco grupos: 1. - el ciclo repartido en ambos lados de la tapa; 2.- tapas con el difunto retratado en una parte y la historia de Jonás en la otra; 3.- los tres hebreos en el horno de Babilonia a un flanco y en el otro los episodios de Jonás; 4.- -en una parte la adoración de los Magos y en la otra el ciclo de Jonás; 5.-Jonás a un lado y en el otro diversas escenas bíblicas.

Con el fragmento conservado no podemos saber con certeza cuál sería la escena correspondiente a la parte izquierda. Podemos excluir la posibilidad del primer grupo, y sabemos que el tercero y el cuarto son los más frecuentes, estando ambos representados en sarcófagos hallados en España, como apreciamos, respectivamente, en el de Martos y en el de Temes. 

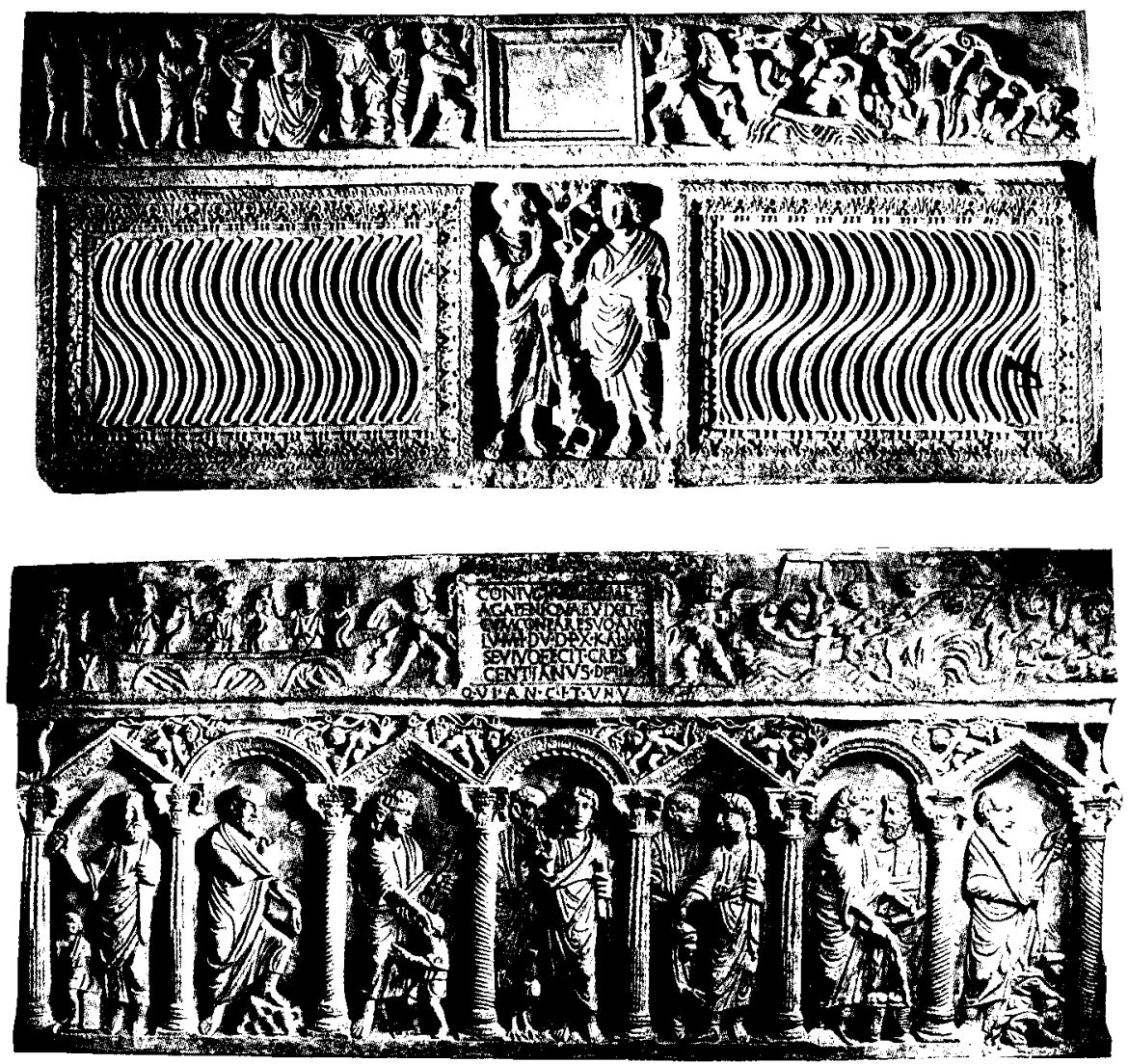

Fig. 3. Sarcofagos completos en cuyas tapas (parte derecha) aparece representado el ciclo de Jonás. I: Laterano 154. II: Laterano 152. (Fotografías del Archivo de los Museos Vaticanos).

De entre todos los grupos, es el tercero el más documentado hasta la fecha, pues conocemos 11 ejemplares (Sotomayor, 1980, pág. 239), de aquí que pudiera ser éste el grupo al que correspondería la historia bíblica que completase la tapa sepulcral de Elda.

\section{CONCLUSIÓN}

El hallazgo de esa tapa de sarcófago romano-cristiano, del primer tercio del siglo Iv, es una muestra más del éxito alcanzado por el proceso 
de aculturación romana, desarrollado sobre el sustrato ibero de la comarca del valle norte de la cuenca media del río Vinalopó. Las huellas de dicho proceso romanizador las hemos podido poner de relieve, en buena parte, con algunas de nuestras investigaciones sobre el poblado iberoromano de El Monastil y el rosario de villas rústicas romanas establecidas en su área de influencia, que están especialmente documentadas desde época augústea (CEE, 1972, págs. 205-208, II, A, B; X-XIII. Poveda, $1984 ; 1985 ; 1986 ; 1987 ; 1988)$.

El castillo de Elda, lugar donde se recogió la pieza paleocristiana, se ubica justamente en las proximidades de las citadas villas, y a escasamente un kilómetro de distancia del núcleo urbano de El Monastil, que se ha identificado con "Ellum", es decir, la población citada como Ad Ello en el Itinerario de Antonino, y que en época visigótica (siglo VII) fue sede de la silla episcopal elotana (Mateu i Llopis, 1956, págs. 31-39. Llobregat, 1973, págs. 46-51; 1977.a, págs. 94 y ss.; 1980, págs. 178179; 1983, págs. 236-237; 1985, págs. 399-400. Azuar, 1981, pág. 41; 1983, pág. 350. Rodriguez Colmenero, 1985, págs. 423-424. Poveda, 1988).

Esa situación de la fortaleza posibilitó que cuando ella necesitó obras de mejora, en época bajomedieval, sus habitantes no tuvieron más que recorrer unos metros para recuperar materiales constructivos de las ruinas romanas próximas, es decir, de las villas o de la ciudad existentes que ahora yacían expuestas al expolio medieval, en virtud del cual pudo reutilizarse una parte, al menos, del sarcófago, pues al estar fabricado en mármol constituía un elemento constructivo de primera calidad. Esto nos explica la ubicación que tenía el fragmento de tapa, cuando se le halló en la cubierta de la cisterna del castillo de Elda.

De la fecha en que se data dicha tapa tenemos claramente probada la existencia de poblamiento hispano-romano en el valle de Elda, que en el siglo IV tiene en actividad, al menos, las villas de Puente del Sambo, de Las Agualejas, de EI Puente II, de Casa Colorá, además de la ciudad de El Monastil (Ello) y las fortalezas del Sambo y de Cámara.

La presencia de una sepultura tan refinada y costosa nos indica que entre ese poblamiento hispano-romano existirian algunos núcleos cristianos de alto rango social, con un estatus económico lo suficientemente elevado como para permitirles importar de Roma semejante objeto, pues el valor intrínseco de éste se incrementaría con un largo transporte en barco, que es el más factible para mercancía tan pesada como es el sarcófago de mármol. Esta idea de comercio marítimo desde Italia hasta las costas españolas la promovieron García y Bellido y Schlunk (respec- 
tivamente, 1949; 1962), teniendo en cuenta que la mayoria de los sarcófagos romanos hallados en España se distribuyen por sus costas y vías de penetración fluvial. El de Elda pudo ser desembarcado en el Portvs Illicitanvs (Santa Pola) y transportado por el valle del Vinalopó hasta aquélla.

Las familias hispano-romanas, ricas gracias a su elevado nivel socioecónomico, como la propietaria del citado sepulcro, influirán de modo importante en la propagación del cristianismo por la comarca.

De hecho, está documentada en El Monastil una importante comunidad paleocristiana, pues se ha hallado un ara sigmática, de mármol blanco, restos de un cancel visigótico, junto a una construcción con ábside que puede corresponderse con un recinto basilical, y, por supuesto, gran cantidad de cerámica de la denominada African Red Slip Ware, de su variedad "paleocristiana", y algunas piezas de cerámica gris provenzal. En algunos de esos objetos cerámicos africanos distinguimos escenas bíblicas y elementos de la iconografía cristiana: sacrificio de Isaac sobre el disco de una lucerna, Daniel con los leones en el fondo interno de un gran plato y chrismones, cruces, etc.

Este lote de material arqueológico ofrece un recorrido cronológico que va desde el siglo IV hasta el VII (Llobregat, 1977.b; 1985, pág. 390. Poveda, 1984; 1988. Reynolds, 1985 ; inédito), y es la confirmación de la existencia de una comunidad cristiana primitiva con suficientes medios y garantías como para pensar en ella en el momento de crear una sede episcopal que suplantase a la de lllici, cuando ésta pertenecia al invasor bizantino. Tal nueva sede es la que aparece en los Concilios Toledanos con el nombre de Ecclesia Elotana (Gams, 1862-79, pág. 74. Llobregat, 1977.a, págs. 94 y ss. Poveda, 1988), por tanto de la ciudad de Elo.

La citada población sería una de las primeras ciudades, de todo el Pais Valenciano, que contaria con una comunidad cristiana, al igual que en Denia, Valencia, La Alcudia de Elche y el Portvs Illicitanvs (Santa Pola), pues todas ellas han dado piezas auténticamente cristianas y fechables en el siglo Iv (Llobregat, 1977.a).

\section{$A D D E N D A$}

Después de entregarse este texto para su publicación, ha aparecido un nuevo estudio sobre sarcófagos paleocristianos entre los cuales se 
recoge el nuestro, pero sin variar prácticamente nada el estudio que presentamos, su autor es M. Sotomayor Muro ("Sarcófagos paleocristianos en Murcia y zonas limitrofes", en Arte y Poblamiento en el SE peninsular. Antig. Crist. (Murcia), V, 1988). Además, hay un nuevo sarcófago del ciclo de Jonás procedente de Tarragona, que no lo hemos podido conocer y cuya publicación por M. D. del Amo está en prensa ("Fragmentos de sarcófago con escenas del ciclo de Jonás procedentes de Tarragona", en las Actas de la III Reunio d'Arqueologia Cristiana Hispanica, Mahón, 1988). 


\section{BIBLIOGRAFIA}

AzuAR, R., 1981: Castellología Medieval Alicantina: Área Meridional. Alicante.

- 1983: «Panorama de la arqueología medieval en los valles alto y medio del Vinalopó (Alicante)", Lvcentvm, II, Univ. de Alicante, págs. 349-383.

BALIL, A., 1975: «Frammenti di sarcofago cristiano nel nord-ovest della Penisola Iberica», Riv. Arch. Crist., núm. 51, págs. 313-316.

BELLI, R., 1985: "Sarcofago con scene del Nuovo Testamento", en Museo Nazionale Romano. Le Sculture, I, núm. 8, 1. a, Roma.

BENOIT, F., 1954: Sarcophages paléochrétiens dÁrles et de Marseille. París.

BRUNStING, H., 1959: “De oud-christelijke Sarcophaag van Leiden», en Oudheidkundige Mededelingen uit Her Rijksmuseum van Oudheden te Leiden, núm. 40 , págs. 35-40.

Brusin, G., 1933: La basilica di Aquileya. Bolonia.

CENTRO EXCURSIONISTA ELDENSE, 1972: “Carta arqueológica del Valle de Elda", $A P L$, XIII, Valencia, págs. 199-208; I-XV.

CHRISTIE, Y., 1984: El mundo cristiano (siglos III-XI), en Historia ilustrada de las formas artisticas, núm. 5, Madrid.

Deichmann, Fr. W., 1967: Repertorium der christlichantiken Sarkophage. I (Rom und Ostia), Wiesbaden.

Delgado, J., 1976: “Tapa de sarcófago paleocristiano en Santa María de Temes-Carballedo, Lugo (España)", Riv. Arch. Crist., núm. 52, págs. 303-324.

ENGEMANN, J., 1973: «Untersuchungen zur Sepulkralsymbolik der spärteren römischen Kaiserzeit», Jahrb. Ant. Christ., núm. 2.

Ferrua, A., 1962: “Paralipomeni di Giona», Riv. Arch. Crist., núm. 38, págs. 7-69. 
Gams, P. B., 1862-79 (reimp. 1956): Die Kirchengeschichte von Spanien. Graz. II, núm. 2.

Garcia Y Bellido, A., 1949: Esculturas romanas de España y Portugal. Madrid, 1979 (reimp. 2. ${ }^{\text {a }}$ ed.) Arte Romano. Madrid.

Gauckler, P., 1910: Catalogue du Musée Alaoui, Musées del l'Algérie et de la Tunisie, 15, Suppl. París.

GeRKE, F., 1940: Die christlichen Sarkophage der vorkonstantinischen Zeit. Berlín.

Ghetti, A.; Ferruua, A.; Josi, E.; KIrschbaum, E., 1951: Esplorazioni sotto la confessione di S. Pietro in Vaticano. Vaticano.

Grabar, A., 1967: El primer arte cristiano (200-395). Madrid.

HAYES, J. W., 1972: Late Roman Pottery. Londres.

KäHLER, H., 1982: Die Frühe Kirche Kult und Kultraum. Ullstein.

KolLWITZ, J., 1933: Die Lipsanothek von Brescia. Berlín-Leipzig.

LawrenCe, M., 1962: "Ships, Monster and Jonah". Amer. Jour. Archa., 66, págs. 289-296.

Llobregat, E. A., 1973: Teodomiro de Oriola. Alicante.

- 1977a: La Primitiva Cristiandat Valenciana. Valencia.

- 1977b: “El altar paleocristiano del Monastil». Alborada, XXIII. Elda, $\mathrm{s} / \mathrm{n}$.

- 1980: Nuestra Historia. II, Valencia.

- 1981: “Un sarcófago cristiano primitivo en Elda». Alborada, XXVII. Elda, s/n.

- 1983: “Relectura del Ravennate: Dos calzadas, una mansión inexistente y otros datos de la Geografía Antigua del País Valenciano". Lvcentvm, II. Univ. de Alicante, págs. 225-242.

- 1985: "Las épocas paleocristiana y visigoda». Arqueología del País Valenciano: panoramas y perspectivas. Univ. de Alicante, págs. 383414.

- 1986a: «Periodo paleocristiano y visigodo». Historia del Arte Valenciano, I (De la Prehistoria al Islamismo). Valencia, pág. 193 ss.

- 1986b: ¿Un art d'inspiració cristiana". Historia de l'Art al Pais Valencià, I, Valencia, pág. 67 ss. (en colaboración con J. F. Yvars).

LoWRIE, W., 1901: "A Jonah Monument in the N. Y. Metropolitan Museum", Amer. Jour. Archa., núm. 5, págs. 51-57.

MATEU I LLOPIS, F., 1956: "Sobre la identificación toponímica de Elota», Homenaje a Millás Vallicrosa, II, Barcelona, págs. 31-39.

MANCINELLI, F., 1981: Catacumbas y basilicas. Los primeros cristianos en Roma. Florencia.

Murray, C., 1981: Rebirth and Afterlife. A study of the trasmutation of some pagan imagery in early christian funerary art. Oxford. 
PALOL, P. DE, 1967: Arqueología Cristiana de la España romana (siglos (V-VI). Madrid-Valladolid.

- 1979: Historia del Arte. III, Barcelona.

PIJOAN, J., 1954: Summa Artis. VII, Madrid.

Poveda, A. M., 1984: La Terra Sigillata de Elda (Alicante). Memoria Licenciatura (inédita). Univ. de Alicante.

- 1985: "Contribución a la economía romana en el valle de Elda (Alicante). Las importaciones de terra sigillata", Alborada, XXXI, Elda, págs. 85-92.

- 1986: "El Monastil" y "Arco Sempere", Arquelogia en Alicante. 1976-1986. Alicante, págs. 104-105; 108-109.

- 1987: "Transformación y romanización del hábitat ibérico contestano de las cuencas Alta y Media del Vinalopó (Alicante)", I Jornadas Internacionales de Arqueología Romana. Granollers (en prensa).

- 1988: El poblado ibero-romano de El Monastil. Introducción históricoarqueológica. Elda.

Recio, A., 1969: «El sarcófago romano paleocristiano de Martos», Antonianum, núm. 44 , págs. 93-136.

REYNOLDS, P., 1985: “Cerámica tardorromana modelada a mano de carácter local, regional y de importación en la provincia de Alicante", Lvcentvm, IV, Univ, de Alicante, págs. 245-267.

-: Tesis Doctoral (inédita).

Rodriguez Colmenero, A., 1985: "La Romanidad Tardía". Historia de la provincia de Alicante, II, Murcia, págs. 394-436.

RumpF, A., 1939: "Die Meerewesen auf den Antiken Sarkophagreliefs", en Die Antiken Sarkophagreliefs, núm. 5, 1. ${ }^{2}$, Berlin.

Schlunk, H., 1962: "Die Sarkophage von Ecija und Alcaudete». Madr. Mitt., núm. 3, págs. 119-151.

Sotomayor, M., 1975: Sarcófagos romano-cristianos de España. Estudio iconográfico. Granada.

- "Un fragmento de tapa de sarcófago paleocristiano en el Museo Sorolla de Madrid». B.S.A.A., XLVI, págs. 233-239.

Stevenson., J., 1979: La Civiltà delle catacombe. Roma.

STOMMEL, E., 1958: "Zum Problem der frühchristlichen Jonasdarstellung". Jahrb. Ant. Christ., núm 1.

STUIBER, A., 1957: Refrigerium interim. Die Vorstellungen vom Zwischenzustand un die frühchristliche Grabeskunst. Bonn.

WILPERT, J., 1929-1936: I sarcofagi cristiani antichi, I-III, Roma. 
Rep. = DEICHMANN, Repertorium...

Sot. = SOTOMAYOR, Sarcófagos...

WS. = WILPERT, I sarcofagi... 